\title{
Tissue Engineering Strategies for Skeletal Repair
}

\author{
Gordana Vunjak-Novakovic, PhD
}

Received: 26 August 2011/Accepted: 15 November 2011/Published online: 14 February 2012

(C) Hospital for Special Surgery 2012

Keywords tissue engineering $\cdot$ bone $\cdot$ cartilage $\cdot$ scaffolds . bioreactors

\section{Introduction}

There is a strong medical need for biological tissue grafts that could reestablish the structure and function of skeletal tissues lost to congenital abnormalities, trauma, and disease. Both the prosthetic devices and autologous tissue grafts are most helpful in providing the necessary tissue structure, but they each have serious limitations [1]. Tissue engineering offers potential to grow fully biological substitutes of native tissues, through the individual and combined use of cells, biomaterial scaffolds, and culture systems [2-5].

\section{The Potential of Bioengineered Human Tissues}

In its most complex incarnation, tissue engineering involves the in vitro generation of living, functional tissue grafts by cultivation of cells on biomaterial scaffolds (designed to serve as a template for tissue formation) in bioreactors (providing environmental control and physical signaling). The design of tissue engineering systems has been guided by biological principles and the need to provide native-like (biomimetic) environments in order to unlock the full biological potential of the cells (Fig. 1). Variations of this

\footnotetext{
G. Vunjak-Novakovic, $\mathrm{PhD}(\bowtie)$

Department of Biomedical Engineering,

Columbia University,

Vanderbilt Clinic 12th floor, Room 12-234, 622 W 168th Street,

New York, NY 10032, USA

e-mail: gv2131@columbia.edu
}

approach resulted in engineered cartilage, bone, and osteochondral grafts [2-4] for implantation studies in animal models and eventual translation into clinical use.

One recently developed approach enables the in vitro cultivation of living human bone grafts customized to match the exact anatomical features of the specific defect, using the patient's own cells (Fig. 2). Importantly, engineered tissues also find application for in vitro screening of cells and regulatory factors and construction of disease models [6]. Furthermore, engineering a tissue under controllable conditions brings new insights into the progression of tissue development and identification of the underlying factors and mechanisms. This knowledge can then also be used to develop therapeutic modalities that involve mobilization and regulation of the host's cells by bioactive acellular implants.

\section{Summary}

Bioengineered culture platforms can provide tight environmental control and the physiological transport and signaling, enabling study of cartilage/bone development, regeneration, and disease under conditions that predict the human in vivo context $[2-4,6]$. The field of bone and cartilage tissue engineering holds significant potential for providing clinically relevant tissue grafts for restoring joint function. These grafts can be personalized using imagingguided techniques and the patient's own cells. As our ability to grow mechanically functional bone and cartilage grafts has progressed, efforts are focusing at tissue interfaces, vascularization of bone, stratification of cartilage, and "conditioning" of grafts to better tolerate the inflammatory environment of an osteoarthritic joint. 


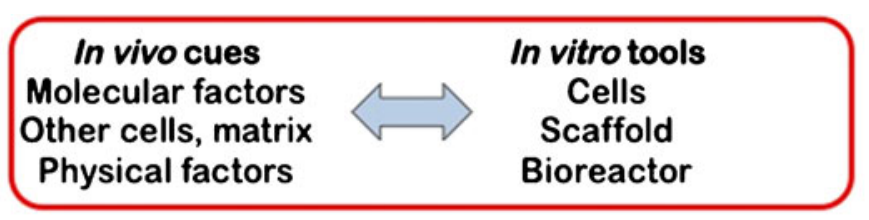

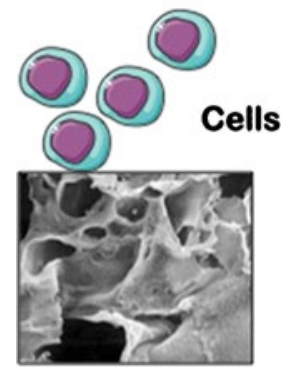

Scaffold
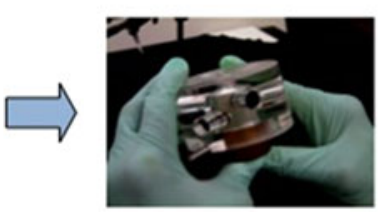

Bioreactor

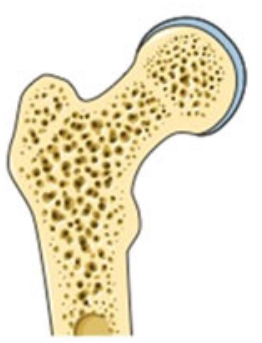

Fig. 1. Biomimetic paradigm. Stem cell fate and function are regulated by the entire context of the cellular microenvironment, through dynamic interactions of the cells with cascades of multiple factors: molecular, structural, and physical. Native-like (biomimetic) cell environments can be engineered by a combined use of a scaffold (a structural and logistic template for cell differentiation and functional assembly) and a bioreactor (environmental control, molecular, and physical signaling)
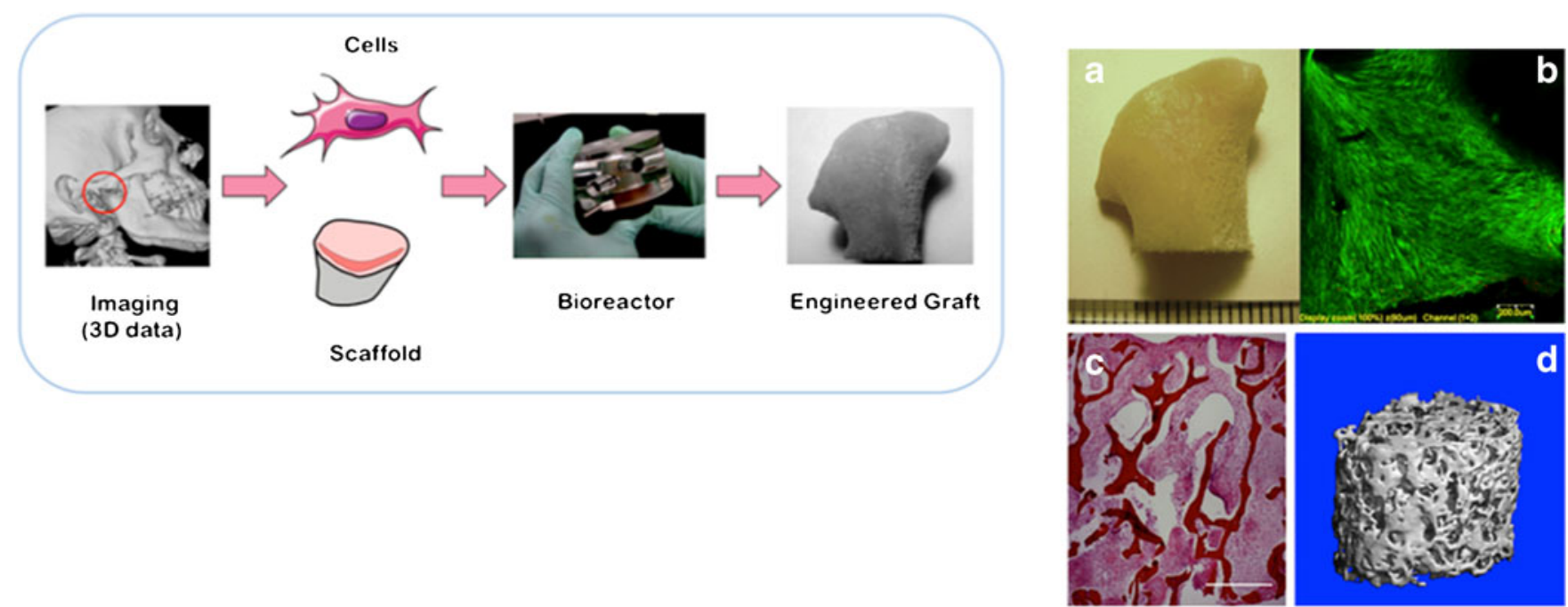

Fig. 2. Engineering of personalized osteochondral grafts. The approach involves imaging-guided design of anatomically shaped composite scaffold and bioreactor chamber, for cultivation of human mesenchymal stem cells. An example is shown for human TMJ condyle consisting of fully viable cells and bone tissue matrix. Adapted from [2]

Funding This study received funding from NIH (DE016525, EB002520, EB011869), NYSCF (CU09-3055), and NYCPF (CU11-1915).

Disclosures The author certifies that she has no commercial associations (e.g., consultancies, stock ownership, equity interest, patent/licensing arrangements, etc.) that might pose a conflict of interest in connection with the submitted article.

\section{References}

1. Finkemeier, C.G., Bone-grafting and bone-graft substitutes. J Bone Joint Surg Am, 2002. 84-A(3): p. 454-64
2. Grayson, W.L., et al., Engineering anatomically shaped human bone grafts. PNAS, 2010. 107(8): p. 3299-304.

3. Hung, C.T., et al., Anatomically shaped osteochondral constructs for articular cartilage repair. J Biomech, 2003. 36(12): p. 185364.

4. Mauck, R.L., et al., Functional tissue engineering of articular cartilage through dynamic loading of chondrocyte-seeded agarose gels. J Biomech Eng, 2000. 122(3): p. 252-60.

5. Quarto, R., et al., Repair of large bone defects with the use of autologous bone marrow stromal cells. N Engl J Med, 2001. 344 (5): p. 385-6.

6. Vunjak-Novakovic G and Scadden D.T. Biomimetic platforms for human stem cell research. Cell Stem Cell 8:252-261, 2011 